\title{
Sustainable Development of Green Paper Packaging
}

\author{
Jiapeng Huang ${ }^{1}$ \\ ${ }^{1}$ South China Agricultural University, Guangzhou, China \\ Correspondence: Jiapeng Huang, South China Agricultural University, Guangzhou, 510642, China. E-mail: \\ 975220710@qq.com
}

Received: March 16, 2017

Accepted: April 10, 2017 Online Published: August 25, 2017

doi:10.5539/ep.v6n2p1

URL: https://doi.org/10.5539/ep.v6n2p1

\begin{abstract}
In recent years, with the rapid development of global industrialization, people's quality of life has improved, and people are no longer satisfied with the quality of goods and purposes, the majority of people even choose goods based on the packaging of goods which cause the situation of excessive packaging become serious. As an important part of manufacturing, packaging industry should emphasize the development of environmentally friendly packaging. Recognized as one of the most promising green packaging materials, paper packaging materials accounted for more than $40 \%$ of packaging materials, however, unsuitable production and recycling of paper packaging pose a threat to the environment and the social economy. For the sustainable development of the paper packaging industry, this essay put forward the concept of "green paper packaging" through literature research. This essay will introduce the proper production and recycling of green paper packaging materials, discuss the structural design of green paper packaging, and looking forward to the development direction of green paper packaging, and come to the conclusion that not only need we use new materials and environmental friendly packaging structures, but also we should attach importance to the production and the recycling of the packaging so as to make sure the entire life cycle of packaging does not harm the human body and the environment.
\end{abstract}

Keywords: green packaging, paper packaging, materials, structural design

\section{Introduction}

Paper is one of the most important packaging materials in both developed and developing. Packaging spending of developed countries often amount to tens of billions of dollars, and China has amounted to more than thirty billion dollars. The proportion of paper and cardboard packaging is more than $1 / 3$ in various kinds of packaging materials and containers all over the world which is more than the proportion of plastic, metal and glass packaging. The output value of paper and paperboard packaging materials accounted for $36 \%$ of the total packaging material all over the world, accounting for $35.6 \%$ of the total output. Since $90 \%$ of the papermaking raw materials come from forest trees and the large amount of waste water that is produced in the process of pulp and papermaking is not controlled perfectly, besides the recycling and structural design is not always reasonable, it is of great significance to achieve the life-cycle low-carbon paper packaging which is based on the concept of green packaging.

Green packaging is also known as "pollution-free packaging" or "environmentally friendly packaging", the international community generally agreed that green packaging should be consistent with 3R1D, that is Reduce, Reuse, Recycle Degradable and other requirements. Chinese scholars believe that green packaging should be able to be reused, recycled or degrades rapidly in the soil which does no harm to human body or the environment in its entire life cycle. In order to realize green paper packaging, packaging materials must be produced environmentally friendly, papermaking wastewater treatment should be spread, and packaging should be recycled rationally after use. Economized structures should be used while advanced materials should be developed at the same time.

\section{The Green Production and Recycling of Paper Packaging Material}

Paper is a non-toxic, pollution-free and non-radiation material with excellent environmentally friendly performance. The pollution of paper packaging mainly comes from pollution emissions from pulp and paper plants or untimely recovery and treatment of waste paper packaging. Green papermaking means less consumption of resources, environmentally friendly and sustainable papermaking industry. It mainly depends on 
the clean production clean production process, the extension of the product life period, and the implementation of advanced production concepts such as waste transforming resources in the paper industry whose main characteristics are cleaner production, circular economy and ecological industry. Therefore, we should set about the development of emission reduction in production and recycling.

\subsection{The Green Production of Paper Packaging Material}

\subsubsection{The Selection of Raw Materials of Pulp}

In order to realize the green production of paper packaging, suitable raw materials for pulp must be chosen at first. Although wood pulp has good environmental performance and physical properties, but excessive use of wood will exacerbate the problem of global forest coverage reduction which is inconsistent with the concept of green packaging. Therefore, reasonable material such as straw or recycled paper should be used to produce paper according to different performance requirements instead of using wood pulp blindly.

Wood fiber is long with few non-fibrous cells and low ash content, so paper made from wood fiber is of high quality, but the excessive use of wood will lead to excessive exploitation of natural forest resources, causing damage to the ecological environment. Therefore, straw and wheat straw pulp can be selected as raw materials of paper which have low precision requirements. Although paper made from straw or regenerated fiber has lower strength, it can protect the natural forest resources on the promise of satisfying the function of packaging.

\subsubsection{Cleaner Production of Pulping}

Because pulping is the first process of papermaking, and the pollution of papermaking mainly comes from the pulping process, cleaner production of pulping plays an important role in the green production of paper packaging. Generally, we should do the following to achieve cleaner production of pulping:

\section{1) The Optimization of Batch Pulping Process}

Let the whole process be operated at optimum temperature, pressure and solid-to-liquid ratio. In order to improve the pulp rate and make the pulp uniform, the raw material should be soaked with hot black liquor in advance while the digester and the steam tube should strengthen heat preservation and heat insulation. Make full use of residual alkali in black liquor and reduce the amount of alkali and steam to save energy. New technologies such as oxygen delignification technology and low-pollution pulping technology should be adopted.

2) Improve the Extraction Rate of Black Liquor

In order to improve the extraction rate of black liquor in the pulp washing to create conditions for the implementation of the alkali recovery and save water, energy and steam while make full use of the waste heat, black liquor should be extracted immediately after water slurry injected in, and the residual heat of waste steam should be used to heat the cold water slurry.

\section{3) Recycling of the Pulping Waste Liquor}

In order to achieve recycling of alkaline pulping black liquor or acid pulping red liquor, namely pulping waste liquor, internal recycle should be taken into account at first, and the waste liquor at last is usually treated by alkali recovery process. At present, the extraction rate of black liquor is about $98 \%$, and the recovery rate is up to 95\%. Typical processes are: black liquor extraction, evaporation, combustion, purification, white liquid recovery. New techniques such as lime method, direct alkali recovery and plasma treatment can reduce the pollution of black liquor effectively.

\subsubsection{Treatment of Waste Liquid}

Pulping waste liquor can be divided into black liquor, grey water and papermaking wastewater. Black liquor comes from cooking pulping process which contributes over $90 \%$ of the total pollution load from paper making wastewater. In the process of alkaline pulping, about $50 \%$ of the fibrous raw material is dissolved in the cooking liquor and turns into black liquor. The main treatment techniques of black liquor at present are alkali recovery method, acid-precipitating method, flocculation and precipitation method, et al. From the principles of these technologies, the treatment of black liquor mainly focused on two aspects: Consume the lignin in black liquor by combustion or pyrolysis. Separate lignin from alkali by physical and chemical methods and multipurpose use lignin. Grey water refers to the wastewater produced from the process of pulp bleaching, screening and purification. The pollutants in the grey water are similar to the black liquor, but concentration of grey water is lower, and grey water contains chloride (bleach) whose pollution factors are COD, BOD, SS. At present, the main treatment methods of middle water include chemical sedimentation method, coagulating-gas-suspension method, chemical oxidation method, ultrafiltration method, active carbon optimization method and biological fluidized bed method. The white water which contains less organic pollution and high fiber content comes from 
the papermaking process, so it needs to be recycled at a maximum extent.

\subsection{Recycling of Paper Packaging Materials}

With shortage of the world's forest resources, people pay more attention to the reduction of native fiber pulp and recycling of waste paper while the treatment techniques of secondary fibers develop constantly. It not only reduces the consumption of raw materials, but also reduces the industrial pollution in the papermaking process. Generally, regenerated papermaking can save more than $40 \%$ of raw material consumption, $50 \%$ of water consumption and $60-70 \%$ energy while air pollution can be reduced by $60-70 \%$, biological oxygen demand can be reduced by $40 \%$, water suspended can be reduced by $25 \%$ and solid waste can be reduced by $70 \%$.

The core problem of waste paper recycling technology is the research of waste paper deinking technology. At present, the most universal technology of waste paper deinking is floatation method. Experience shows that the flotation method is the most effective method for the removal of ink particles with diameters between 10 and $100 \mu \mathrm{m}$. Compared with the washing method, the flotation method has the advantages of high fiber yield, low water consumption, less waste water, but products with low whiteness and high ash content, and the method is complicated to operate while consume large power.

\section{Green Paper Packaging Structural Design}

The material of paper packaging has good environmental performance and is easy to recycle, but reasonable structure also plays an important part in green paper packaging. Reasonable structure of packaging can make packaging easy to produce, process and recycle, which can make paper packaging greener and more environmentally-friendly.

\subsection{Reduction Design}

On the premise of ensuring the performance, packaging structure should be simplified while excessive packaging must be avoided. In order to reflect the high value of the goods, there is many excessive packaging on the market at present.

In order to increase the value of the goods, Multi-layer packaging or expensive materials are used blindly resulting in the packaging costs even higher than the value of goods. Such packaging not only confuses consumers, but also wastes more resources, increase production costs and recovery difficulties, and are inconsistent with the development direction of green packaging. Therefore, packaging structure should be simplified on the premise of ensuring the performance. MUJI is the representative of minimalist packaging design on the market which emphasizes the quality of goods. The simplest structure of the paper bag and the very little ink printing area bring consumers simple and natural beauty, and greatly reduce the packaging cost and the difficulty of recycling at the same time which meets the development direction of green packaging. In addition, design and typesetting of unfolded drawings can be improved to reduce leftover pieces as far as possible.

\subsection{Adopt Easy Transporting Structures}

Reduce transportation cost and energy consumption on the premise of ensuring the performance of packaging. For example, we should try to use square packaging instead of circular packaging to minimize the wasted space during transportation. For example, octagonal boxes, such as pizza boxes can save $10 \%$ of packaging materials.

\subsection{Adopt Easy Disassembly Packaging Structures}

In order to satisfy the protective function or meet consumer's aesthetic needs, some special commodity packaging needs to adopt multilayer packaging. Packaging should be easy to disassemble so as to separate different materials easily and reduce the cost, difficulty and workload of recycling. For example, the standard shaped box is easier to disassemble than the specially shaped box, and the folding carton is easier to disassemble than the paste carton.

\subsection{Adopt Multifunctional Packaging Structures}

Multifunctional packaging can be used as an entertainment or functional product instead of being thrown away. Compared with other packaging, multifunctional packaging meet the development direction of green packaging, realize multi-purpose and reusable packaging, and reduce the waste of resources and processing costs effectively. For example, in an activity named "2ndlives" which was organized by the Coca-Cola Company in Thailand and Vietnam, 16 kinds of bottle cap which can turn Coke bottle into water pistol, watering can, dumbbell, rattle or other small toys are offered to consumers for free. These bottle caps let bottles can be reused without processing.

\section{New Materials of Green Paper Packaging}


Due to the diversification of modern goods, commodity paper packaging is also required to have different properties. In order to meet the needs of the market, more and more environmentally friendly paper packaging materials with special properties are developed recently. The development of new materials has gradually become the development trend of paper packaging.

1) Edible Paper Packaging

Edible paper packaging is a kind of paper packaging material made of edible material such as starch, protein and plant fiber. Japan is the first to develop vegetable paper. Sakai Ri Institute of Chemistry has successfully extracted protein made of pure food fiber from bean dregs, and then processed into edible packing paper, fruits paper, vegetables paper, seaweed paper etc. Edible paper packaging is mainly used in the inner packaging of food and disposable beverage cups. Due to the wide source of packaging materials, it can greatly reduce the environmental pollution.

\section{2) Vacuum Plated Canton Paper}

Because vacuum plated canton paper has bright color, strong sense of metal, and gorgeous appearance, it can replace a large area of bronzing of prints and be widely used in cosmetics packaging, wine packaging, high-grade beer labels, food packaging and tea caddy. It adopts vacuum method and cover the cardboard surface with a layer of thin and compact aluminum film whose thickness is $0.25 \mathrm{um}-0.3 \mathrm{um}$, and the consumption of aluminum is only $1 / 300$ of aluminum foil composite paper. Vacuum plated canton paper is an environmentally friendly packaging material for the reason that aluminum is recyclable and biodegradable itself, and vacuum plated canton paper can reduce the consumption of metal resources. For example, packaging of Philips' energy-saving lamps has replaced composite anti fake film which contains plastic film with vacuum plated canton paper for the sustainable development since the second half of 2003.

3) Foam Wrapping Paper

In December 2004, German Bremen Paspa (PSP) Company developed a new process for the production of foam paper, can replace foamed plastic, effectively reducing the environmental pollution and waste of resources. To produce foam wrapping paper which uses old scrap paper and flour as raw material, recycled scrap paper should be cut into strips and turn into fibrous pulp at first. Secondly, the pulp should be mixed with flour in the proportion of 2:1. At last, the mixed paper pulp should be injected in extruding machine and turn into cylindrical particles. In the extrusion process, the raw material turns into foam paper under the effect of water vapor. Using foam paper particles as raw materials, a variety of packaging can be produced according to different requirements. Relatively speaking, the production process of foam paper is simpler than foamed plastic, because foam paper can take shape once. As the production of foam paper only needs water vapor instead of chemical additives, and the used foam paper can also be recycled, so both production and use of foam paper are good for the environment. From the point of view of economic benefits, foam paper is about $10 \%$ cheaper than foamed plastic producing the same amount of packaging materials.

\section{Conclusions}

1) Introduce the whole process of green production of paper packaging materials from raw material selection to recycling.

2) Introduce four kinds of low carbon environmental protection green paper packaging structure.

3) Introduce three new materials of green paper packaging rising at home and abroad recently.

In order to realize the green paper packaging, not only need we use new materials and environmental friendly packaging structures, but also we should attach importance to the production and the recycling of the packaging so as to make sure the entire life cycle of packaging does not harm the human body and the environment.

\section{References}

Chen, J. B. (2004). The Enormous World Market of Paper Packaging. China New Packaging, (4), 47-49.

Cheng, P. F., \& Wang, Q. L. (2006). Research and Development Trend of Paper Packaging Materials. China Packaging, 5, 39-42.

Dai, H. M., \& Dai, P. Y. (2011). Achievements, Problems and Countermeasures of Chinese Green Package (Part One). Packaging Journal, 3(1), 1-6.

Hu, H. H. (1999). Deinking Technology and Deinking Chemicals. Chemistry \& Bioengineering, (4), 34-35.

Hu, K. T., \& Kou, S. L. (2010). Green Papermaking and Paper Chemicals Industry under the Background of Low Carbon Economy. China Pulp \& Paper Industry, 31(17), 8-13. 
Li, J. (2006). New Members of Wrapper Paper. China Packaging Industry, (7), 19-19.

Liu, G. X. (2010). Green Production of Paper Packaging Materials. China Packaging, 30(8), 36-37.

Liu, Y. (2015). Research on the Sustainability of Green Packaging Design. China Packaging Industry, (22).

Shu, M. J., Li, Y. M., Xie, C., \& Chen, Z. H. (2002). Application of the Inter-loop Aerobic Three-phase Fluidized Bed to the Treatment of middle-stage Effluent in Paper Mills. Industrial Water Treatment, 22(5), 24-27.

Sun, D., Liu, M.-C., \& Bie, R.-S. (2004). Pollution and Treatment Techniques of Papermaking Wastewater. Boiler Manufacturing, (2), 59-60.

Sun, P. P. (2007). New Progress and Development Trend of Functional Wrapping Paper. Shanghai Paper Making, 6, 31-33.

Xia, J., \& Wang, T. (2004). Recycling of Waste Papers in Municipal Domestic Refuse. China Environmental Protection, (6), 28-29.

Zhou, H. (2006). The New Environmental Protection Materials -- Vacuum Aluminum Plated Paper. China Printing Materials Market, 10, 27-28.

\section{Copyrights}

Copyright for this article is retained by the author(s), with first publication rights granted to the journal.

This is an open-access article distributed under the terms and conditions of the Creative Commons Attribution license (http://creativecommons.org/licenses/by/4.0/). 